University of Wollongong

Research Online

Faculty of Commerce - Papers (Archive)

Faculty of Business and Law

$1-1-2008$

\title{
Ethical ideologies of senior Australian managers: an empirical study
}

Mario Fernando

University of Wollongong, mariof@uow.edu.au

S. Dharmage

University of Melbourne

Shamika Almeida

University of Wollongong, shamika@uow.edu.au

Follow this and additional works at: https://ro.uow.edu.au/commpapers

Part of the Business Commons, and the Social and Behavioral Sciences Commons

\section{Recommended Citation}

Fernando, Mario; Dharmage, S.; and Almeida, Shamika: Ethical ideologies of senior Australian managers: an empirical study 2008.

https://ro.uow.edu.au/commpapers/459

Research Online is the open access institutional repository for the University of Wollongong. For further information contact the UOW Library: research-pubs@uow.edu.au 


\title{
Ethical ideologies of senior Australian managers: an empirical study
}

\begin{abstract}
Forsyth's (1980) Ethics Position Questionnaire and Hunt et al.'s (1989) Corporate Ethical Value Questionnaire are used to examine the ethical ideologies of senior managers from organizations listed in the Australian Stock Exchange. The results indicate how corporate ethical values, religion, gender and age are related to the idealism and relativism of senior Australian managers. After discussing the results, limitations of the study are offered. Finally, managerial implications are provided and recommendations for future research are given.
\end{abstract}

\section{Keywords}

Australia, idealism, relativism, corporate ethical values, managers

Disciplines

Business | Social and Behavioral Sciences

\section{Publication Details}

This article was originally published as Fernando, M, Dharmage, SC, Almeida, S, Ethical ideologies of senior Australian managers: an empirical study, Journal of Business Ethics, 82(1), 2008, 145-155. 


\section{Ethical Ideologies of Senior Australian Managers: An Empirical Study}

Mario Fernando (PhD, MBA, BCom) is a Senior Lecturer at the School of Management and Marketing, University of Wollongong, Australia, and a Visiting Research Fellow of the Centre for Studies in Religion and Society, University of Victoria, Canada. His current teaching and research focus is on organizational virtuousness, workplace spirituality, ethical and spiritual leadership. His most recent work is due to be published in a book titled Spiritual Leadership in the Entrepreneurial Business: A Multifaith Study (2007, Edward Elgar).

Shyamali C. Dharmage (PhD, MD, MSc, MBBS) is a Senior Lecturer at the Centre for MEGA (Molecular, Environmental, Genetic \& Analytic) Epidemiology, School of Population Health, University of Melbourne, Australia. Her main research focus is on the epidemiology of allergy and airway diseases. In addition, she contributes to the methodological and analytical aspects of research projects in other areas.

Shamika Almeida (MSc, MBA) is a PhD candidate in the Work and Organisational Studies Discipline at the University of Sydney, Australia. Her research is on social and human capital issues. 


\title{
Ethical Ideologies of Senior Australian Managers: An Empirical Study
}

\begin{abstract}
Forsyth's (1980) Ethics Position Questionnaire and Hunt et al.'s (1989) Corporate Ethical Value Questionnaire are used to examine the ethical ideologies of senior managers from organizations listed in the Australian Stock Exchange. The results indicate how corporate ethical values, religion, gender and age are related to the idealism and relativism of senior Australian managers. After discussing the results, limitations of the study are offered. Finally, managerial implications are provided and recommendations for future research are given.
\end{abstract}

\section{Keywords:}

Australia; idealism; relativism; corporate ethical values; managers 


\section{Ethical Ideologies of Senior Australian Managers: An Empirical Study}

\section{INTRODUCTION}

Karande, Rao and Singhapakdi (2002) examined the ethical differences between American, Malaysian and Australian marketers. Several propositions were tested that link the influence of the various dimensions of culture, corporate ethical values, gender and age to variations in levels of idealism and relativism in ethical decision-making. The present study is developed on Karande et al.'s (2002) research design, and forms the basis for the propositions postulated below.

This paper aims to report the findings of a nation wide study conducted on the ethical decision-making of managers from organizations listed in the Australian Stock Exchange. It provides input on how corporate ethical values, religion, gender and age are related to the idealism and relativism of managers. This paper is organized as follows: first, we review the literature on ethical ideologies and decision-making. In the second section, we present the theoretical foundation of the study and develop the hypotheses. In the third section on methodology, details about the sample, the measures and analysis are provided. Next, results are presented. After discussing these results, limitations of the study are offered. Finally, managerial implications are provided and recommendations for future research are given.

\section{ETHICAL IDEOLOGIES AND DECISION-MAKING}

Recent corporate failures suggest that although managers are equipped with an array of management tools to deal with day-to-day management situations, during ethically challenging situations, these tools need to be complemented with other decision-making aides. These ethically challenging decision-making situations tend to lead to ethical dilemmas, and are 
grounded in the conditions and factors related to the decision maker, the situational circumstances and the decision-making process itself. Numerous guidelines are offered to organisational members to systematically analyse ethical dilemmas (Loewenberg and Dolgoff, 1996; Reamer, 1990; Abramson, 1985).

Business ethics researchers have examined personal moral philosophies (Karande et al., 2002) or personal ethical ideologies (Henle et al., 2005) as a factor that has considerable impact upon decisions. In this paper we adopt Henle et al.'s definition of ethical ideology: "a system of ethics used to make moral judgments, which offers guidelines for judging and resolving behavior that may be ethically questionable.” (2005, pp.219). Several researchers have proposed theories on the individual differences in ethical ideology (e.g. Kohlberg, 1983; Hogan, 1973; Rest et al., 1974). Forsyth (1980) was able to explain these theories on "two general dimensions: idealism and relativism." (pp.175).

Idealism is defined by Forsyth as the degree to which individuals "assume that desirable consequences can, with the right action, always be obtained" (1980, pp. 176, emphasis in original). He explains that idealistic individuals feel that harming others is always avoidable, and they would rather not choose between the lesser of two evils which will lead to negative consequences for other people (Forsyth, 1992, pp. 462). Relativism on the other hand is defined by Forsyth (1980, pp. 175) as "the extent to which an individual rejects universal moral rules" when making ethical judgments. These relativistic individuals "generally feel that moral actions depend upon the nature of the situation and the individuals involved, and when judging others they weigh the circumstances more than the ethical principle that was violated" (Forsyth, 1992, pp. 462). Rather than contraries, Forsyth (1980) and others (Forsyth et al., 1988; Davis et al., 2001) have demonstrated that idealism and relativism are orthogonal dimensions of ethical 
ideology.

High or low idealism and relativism fall into one of the four ethical ideologies: situationism, absolutism, subjectivism or exceptionism (Forsyth, 1980). Each of the four typologies draws from a specific school of thought in philosophy. According to Forsyth (1980), the situationists and subjectivists (low idealism/high relativism) support an ideology related to ethical scepticism; absolutists (high idealism/low relativism) tend to agree with deontology and exceptionists (low idealism/low relativism) are more compatible with the teleological ethical philosophy.

Idealism and relativism have been extensively used in the business ethics literature. They have been shown to influence organizational deviance (Henle et al., 2005); perceived ethical problem (Hunt and Vitell, 1986); ethical intention and perceived moral intensity (Singhapakdi et al., 1999); ethical sensitivity (Sparks and Hunt, 1998); perceived importance of ethics and social responsibility (Singhapakdi et al., 1995) and ethical judgement (Vitell and Singhapakdi, 1993).

\section{THEORETICAL FOUNDATION AND HYPOTHESES}

Based on the research design of Karande et al. (2002), in this section it is proposed that the variation in idealism and relativism of Australian managers is explained by corporate ethical values and individual characteristics of religion, gender and age (Figure 1).

Insert Figure 1 about here

\section{Corporate Ethical Values}

Karande et al. (2002) observe that most models of ethical decision-making posit that organizational factors such as an organization's ethical values influence a manager's ethical decision-making (Hunt and Vitell, 1986, 1993; Ferrell and Gresham, 1985; Trevino, 1986). 
Corporate ethical values (CEV) has been defined by Hunt et al. (1989) as a composite of the individual ethical values of managers and both the formal and informal policies on ethics of the organization. Although a high CEV score means that the manager works in an organization with higher corporate ethical values (Karande et al., 2002), it is the manager's perception of the extent of corporate ethical values.

Karande et al., (2002) comment that as organizational ethical values reflect a shared understanding regarding what is correct behavior and how ethical issues will be handled in the organization, these organizational ethical values can be expected to influence the moral philosophy of managers. For example, corporate ethical values have been shown to influence the standards that delineate the "right" things to do and the things "worth doing" (Jansen and Von Glinow, 1985); organizational success (Hunt et al., 1989); superior job performance (Weeks and Nantel, 1992). Karande et al. (2002) citing Laczniak and Inderrieden (1987) points out that the relationship between corporate ethical values and moral philosophy depends upon the effective enforcement of codes of ethics. Well enforced consequences for misconduct such as rewarding ethical conduct and punishing unethical conduct are likely to make managers consider the morality of their actions. However, at the same time, the usefulness of ethics codes to promote and demand ethical behavior from organizational members has been questioned. Those who believe that right action must be internally motivated question the value of codes of ethics to increase the ethicality of organizational members (e.g. Ladd, 1991). However, over a period of time, with the effective enforcement of codes of ethics, it is likely that the organizational members' perceptions of CEV and the resulting behavior will be aligned with the expected ethical standards set by the ethics code. Those who are unable and unwilling to meet the higher ethical standard are likely to ultimately leave the organization. Consequently, the members who 
remain are likely to be more idealistic than those managers who work in companies with lower corporate ethical values.

Singhapakdi et al. (1999) note that managers in organizations with higher levels of ethical values should have a higher moral standard, on average, than those in organizations with lower levels of ethical values, and therefore be more committed to finding ethical solutions to moral problems (i.e. be more idealistic) and rely more on rules and guidelines (i.e. be less relativistic). They found a positive corporate ethical values-idealism relationship but an insignificant relationship between corporate ethical values and relativism. Therefore, we hypothesize that:

Hla. Corporate ethical values are positively related to the idealism of managers. H1b. Corporate ethical values are negatively related to the relativism of managers.

\section{Religion}

Religiosity has been found to influence a marketer's ethical decision-making process (Hunt and Vitell, 1993; Longnecker et al., 2004). Hunt and Vitell state, “Unquestionably, an individual's personal religion influences ethical decision-making. A priori, compared with nonreligious people, one might suspect that the highly religious people would have more clearly defined deontological norms and that such norms would play a stronger role in ethical judgments" (1993, pp. 780). Longnecker et al.'s (2004) US study of 1234 business leaders also found evidence of a significant religious factor in ethical decision-making. However, general categorization of respondents into Protestant, Catholic and Jewish faiths did not detect any relationships of substantial importance.

In contrast, Arslan's (2001) study of 277 Protestant, Catholic, and Muslim managers to examine whether religious denomination influences an individual's work ethic found that there is 
a significant difference between Muslim and other groups. Muslims exhibited Max Weber's highest Protestant Work Ethic level, followed by Protestants, then Catholics. Singhapakdi et al. (2000) claim that religiosity affects the ethical decision-making process in different ways and a more religious person would have a higher moral standard than a less religious person. According to the 2006 census (ABS, 2007), the predominant religion in Australia is Christian (64\%). Therefore, we hypothesize that:

H2a. Christian managers are more idealistic than others.

H2b. Christian managers are more relativistic than others.

\section{Gender}

Researchers have identified gender as an important demographic variable influencing an individual's ethical decisions (Henle et al., 2005; Karande et al., 2002). For example, in a metaanalysis using data from more than 20,000 respondents in 66 samples, Franke et al. (1997) found that women are more likely than men to recognize that a business practice involves a moral issue. In a study of American marketers, Singhapakdi et al. (1999) found even though women were found to more idealistic and less relativistic than men, the gender effect was non-significant and small, and therefore makes an investigation into this issue more important. Based on Gilligan's (1982) work, it can be argued that "the ethic of caring" exhibited by women would lead them to believe that taking actions that are detrimental to others is avoidable; therefore, women exhibit greater idealism. Men, on the other hand, tend to be more "independent, masterful, assertive, and instrumentally competent" (Eagly and Wood, 1991, pp. 309), and therefore could attribute certain actions to circumstances in order to demonstrate their competence. With a more communal character, women might have no motivation to do so. In other words, men would be expected to be more relativistic than women. These arguments, 
according to Karande et al. (2002), are compatible with the observations of Forsyth et al. (1988, pp. 244) that "the ethic of caring appears to be conceptually similar to the idealism dimension" of moral philosophies and "may also be inversely related to relativism if individuals feel that caring for others is a fundamental moral principle". These differences are also consistent with arguments made in the section on the effect of cultural differences about the effect of masculinity/femininity on idealism and relativism. Therefore, we adopt Karande et al.'s (2002) and hypothesize that:

H3a. Women tend to be more idealistic than men.

H3b. Women tend to be less relativistic than men.

\section{Age}

Using Kohlberg's (1981) cognitive moral development theory, Karande et al. (2002) observe that an individual's cognition, emotion, and judgment may change as he or she moves through stages of moral development. They argue that age and ethical behavior should be related because as individuals move through stages of moral development, moral development occurs mainly due to life experiences. Karande et al. (2002) cite other researchers to support this argument; people tend to become more ethical as they grow older (Terpstra et al., 1993); as people age they tend to become less concerned with wealth and advancement and more interested in personal growth (Hall, 1976); older managers tend to be exposed to a variety of ethical problems and become more sensitive to the harm that ethical transgressions can do to the organization and its stakeholders (Singhapakdi et al., 1999). Therefore, based on Karande et al. (2002), we hypothesize that:

H4a. A manager's age is positively related to his or her idealism.

H4b. A manager's age is negatively related to his or her relativism. 


\section{METHODOLOGY}

\section{Study Population and Sample}

3300 electronic mail invitations were sent to senior managers randomly selected from organizations listed in the Australian Stock Exchange. This paper reports the findings from the completed responses generated from this first mail out. Another mail out will be conducted during the concluding stage of this study

Potential participants were invited to log onto a web site and complete the "Ethical Decision-making Questionnaire". 54 electronic mails were returned. 154 opted out from the mailing list. A total of 463 invitees logged onto the web site. 80 completed responses were recorded. $86 \%$ of the respondents were at the General Manager level and above.

\section{Measures}

Idealism and relativism. In this study, Karande et al.'s (2002) adoption of Forsyth's (1980) ethics position questionnaire (EPQ) was used to measure the levels of idealism and relativism (see the Appendix). The EPQ follows Forsyth's view that individual differences as predictors of moral judgment may be described most parsimoniously by taking into account two basic dimensions of personal moral philosophies, idealism and relativism. The EPQ consists of two scales to measure idealism and relativism. The original EPQ contains ten questions concerning idealism, and another ten questions concerning relativism. This questionnaire allocates respondents to different ethical groups, by evaluating their responses and averaging their total scores in both segments. Idealism and relativism are conceptually independent, and individuals may be high or low on either dimension (Forsyth, 1992).

Deviating from Karande et al.'s (2002) study, instead of a nine-point Likert scale, a fourpoint scale was used for measurement, with 1 indicating "strongly agree" and 4 indicating 
"strongly disagree". Karande et al. (2002) assessed the convergent and discriminant validity of the idealism and relativism measures. They found that each scale was judged to have convergent validity if it exhibited unidimensional factor structures and had significant factor loadings $(\mathrm{p}<0.01)$ greater than 0.5 for all indicators of the construct. As in Karande et al.'s study (2002), we used eight relativism and seven idealism items. For each respondent, the idealism and relativism scores were computed by summing the items.

Corporate ethical values, religion, gender and age. The corporate ethical values (CEV) scale developed originally by Hunt et al. (1989) was used in this study to measure corporate ethical values. The scale was designed to reflect "a composite of the individual ethical values of managers and both the formal and informal policies on ethics of the organization" (Hunt et al., 1989). The CEV scale has five items (see The Appendix) and was measured using a four-point Likert scale with 1="strongly agree" and 4="strongly disagree". As in Karande et al.'s (2002) study, for each respondent, the CEV score was obtained by summing all CEV items (with items 1 and 2 reverse-coded). According to Karande et al. (2002), the CEV scale exhibited good convergent validity with all factor loadings significant and greater than 0.5. In addition, information on demographic variables such as religion, age and gender was collected.

\section{Analysis}

SPSS 13 was used to analyse data. As idealism, relativism and CEV were not normally distributed, these variables were log transformed. Pearson correlation and paired samples $t$ tests were used to examine the association between these three variables and Analysis of Variance (ANOVA) was used to compare these between the categories of nominal and ordinal variables. Multiple linear regression was conducted to examine the relevant associations while adjusting for 
confounding factors. The statistical significance of the relevant associations was defined by using $\mathrm{p}<0.1$ cut off.

\section{RESULTS}

Table 1 describes the profile of the study sample. $47.5 \%$ of the participants belonged to the age category of 41-50 and only one person was less than 30 years old. Majority of the managers were males $(86.2 \%)$ and Christians $(73.8 \%)$. Table 2 provides the descriptive measures of the values of the idealism, relativism and corporate ethical values (CEV) for the study sample. The intra-individual difference between the idealism and relativism was statistically significant (geometric mean=1.37; 95\% CI 1.27-1.47 p<0.001)

Insert Table 1 about here

Insert Table 2 about here

H1a states that CEV positively relates with managers' idealism and H1b states that CEV negatively relates with relativism. Results indicate a negative relationship between CEV and relativism (Pearson $\mathrm{r}=-0.24 \mathrm{p}=.06$ ) but there is no association between CEV and idealism. The association between $\mathrm{CEV}$ and relativism remained statistically significant even after adjusting for age $(-0.2 \mathrm{p}=0.07)$. Therefore, H1a is not supported but H1b is supported.

$\mathrm{H} 2 \mathrm{a}$ states that Christian managers are more idealistic than others, and $\mathrm{H} 2 \mathrm{~b}$ that Christian managers are more relativistic than others. Results show that religion was significantly related to relativism but not to idealism and CEV. Christian managers were more idealistic than others, 
which was statistically significant (Table 3). Therefore, H2a is supported. However, Christian managers were less relativistic than others. Therefore, $\mathrm{H} 2 \mathrm{~b}$ was not supported.

\section{Insert Table 3 about here}

H3a states that women are more idealistic than men, and H3b states that women are less relativistic than men. Results indicate that gender is not significantly related to either idealism or relativism. Therefore, $\mathrm{H} 3 \mathrm{a}$ and $\mathrm{H} 3 \mathrm{~b}$ are not supported.

$\mathrm{H} 4 \mathrm{a}$ and $\mathrm{H} 4 \mathrm{~b}$ hypothesize the effect of age on idealism and relativism. While results indicate no relationship between age and idealism, age was found to be significantly negatively related to relativism and significantly positively related to CEV (Table 3). Therefore, while H4a is not supported, H4b is supported.

\section{DISCUSSION}

Senior Australian managers showed a idealism geometric mean of 22.9 and a relativism geometric mean of 16.4. While the results found a negative relationship between CEV and relativism, it found no association between $\mathrm{CEV}$ and idealism. The association between CEV and relativism remained significant even after adjusting for age. $47.5 \%$ of the respondents were between the ages of 41-50 with only one person being under the age of 30. Earlier, we identified previous research supporting that people tend to become more ethical as they grow older (Terpstra et al., 1993; Hall, 1976; Singhapakdi et al., 1999). However, the significance of the CEV-relativism association after adjusting for age suggests that more than age, other variable/s could influence this relationship. $86 \%$ of the respondents were at the General Manager level and above. It is likely that these senior managers would have been responsible for formulating and executing ethics codes in their respective organizations. Noting that the CEV is based on the 
perceptions of these senior managers, consequently, there would have been high awareness of CEV resulting in a negative relationship with relativism. These results on CEV's relationship with idealism and relativism could be contrasted with similar studies. In Karande et al.'s (2002) study, CEV influenced both idealism and relativism but Singhapakdi et al. (1999) found that idealism was significantly influenced by CEV but not relativism.

Taylor (2003) found that from Hofstede's five dimensions, individualism correlated mostly with Christianity. As per the 2006 national census, 64\% of Australians are Christians (ABS, 2007). With a high individualism index (90), Australians have a strong belief in individuality, with individual's rights being paramount within the society. They are expected to form a larger number of looser relationships with little concern for others, which means that they will be less relativistic. Supporting Taylor's (2003) findings, the current study found that Christian managers are more idealistic than others.

The results on gender could be due to women managers in the sample might be as aggressive and competitive as male managers, and vice versa. These results can be compared with the mixed results for similar hypotheses in Karande et al.'s study (2002). In Singhapakdi et al. (1999) study of American marketers, the gender-relativism relationship was found to be nonsignificant. While results indicate no relationship between age and idealism, age was found to be negatively related to relativism. These results are consistent with the findings for the level of work experience by Karande et al. (2002) and Singhapakdi et al. (1999) and support the view that people tend to become more ethical as they grow older.

As with any empirical study, there are several potential limitations of this study. The low response rate could undermine the predictive validity and generalizability of the findings. Therefore, the findings of this study should be viewed considering the low response rate. The 
low response rate to the first mailout could be due to several factors. One could be the nature of the study. Questions on personal and corporate ethical orientations could have precipitated a rejection to the invitation to participate in the study. The seniority of the sample and organization policies could also have contributed to the low response rate.

It is likely that the responders are different to the non-responders creating some selection bias, which limits the generalizability of the results to the rest of the study population. Consequently, it is possible that responders to ethical studies of this nature would be keen to behave ethically while non-responders may not. This warrants further examination. By comparing the study sample with the standard profile of the Australian manager, we could determine the similarity or deviance from the standard. A significant deviation from the standard is likely to further lend support to the assertion that ethical studies attract responders who are ethically minded and discourage others who are not so ethical. It should be noted that the small number of participants may also have reduced the power of the study contributing to some of the null findings. Another limitation of this study is that it did not account for the heterogeneity of the sample. The Australian population is heterogeneous with a substantial recent immigrant community. The results of our study have to be interpreted with the knowledge that this within country variation is not accounted for.

\section{IMPLICATIONS}

Despite these limitations, the findings of this study investigating the application of idealism and relativism in Australian managers has potential implications for both Australian and international organizations. This study identified levels of idealism and relativism in Australian managers, and explained their variation across managers with differences in corporate ethical values, religion and age. 
Corporate ethical values had a negative relationship with relativism. This would support the view that increased employee awareness of ethical codes is likely to prevent those making decisions from a relativist orientation. However, blindly implementing ethics codes without adequate integration of personal moral philosophies would not improve the ethical climate of organizations. As Henle et al. (2005) observe, managers' moral philosophies may make them less or more willing to adhere to organizational policies, which means that managers are likely to respond to ethically challenging situations in disparate and idiosyncratic ways. Not only should managers be made aware of corporate ethical values through ethics codes but also recognizing managers' ethical ideologies when formulating ethics codes could avoid misinterpretation and misapplication of organizational values and intentions.

Effective ethics training programs could generate consistent responses from managers to ethically challenging situations. These programs should help managers to recognize preferential ethical ideologies and the resulting strengths and weaknesses of their decisions. Also, increasing their sensitivity to the differences in ethical ideologies of their counterparts should help them to anticipate actions of colleagues as well as Australian and overseas business associates. Training could identify the link between managers' preferential ethical ideologies and potential conflicts. Effective interventions should make managers aware of these differences and develop ways of avoiding such potential conflicts.

In scouting for Australian managers, both local and international organizations may look for potential recruits who could adopt corporate ethical values easily. This would ensure a smoother transition period for the new recruit. Also, when making recruiting decisions, it will be useful for employers to recognize that Australian managers show decreasing relativism with age. 
This study can be extended in several ways. Useful insights could be generated from examining the interplay between individualism/collectivism and idealism/relativism of managers from different cultures. Also, examining the nature of the relationship between ethics codes and ethical ideologies of Australian and other managers could add useful insights to the ongoing debate on the effectiveness of ethics codes. Lastly, future research could examine the influence of managers' ethical ideology on conflict resolution, organizational hypocrisy, emotional intelligence, moral reasoning and organizational virtuousness (see Fernando, 2007).

*Acknowledgement: Research assistance provided by Renae Helmund is gratefully acknowledged. 


\section{APPENDIX}

\section{Measurement Scales for Idealism, Relativism, and Corporate Ethical Values}

Source: European Journal of Marketing, 36(7/8), Karande, K., C. P. Rao and A.Singhapakdi: 'Moral Philosophies of Marketing Managers:A Comparison of American, Australian and Malaysian Cultures', pp. 768-791, Copyright (2002) with permission from Emerald.

\section{Idealism (Forsyth, 1980)}

1. A person should make certain that their actions never intentionally harm another even to a small degree.

2. Risks to another should never be tolerated, irrespective of how small the risks might be.

3. The existence of potential harm to others is always wrong, irrespective of the benefits to be gained.

4. One should never psychologically or physically harm another person.

5. One should not perform an action which might in any way threaten the dignity and welfare of another individual.

6. If an action could harm an innocent other, then it should not be done.

7. The dignity and welfare of people should be the most important concern in any society.

8. It is never necessary to sacrifice the welfare of others.

\section{Relativism (Forsyth, 1980)}

1. What is ethical varies from one society to another.

2. Moral standards should be seen as being individualistic, what one person considers to be moral may be judged to be immoral by another person.

3. Different types of moralities cannot be compared as to "rightness".

4. Questions of what is ethical for everyone can never be resolved since what is moral or immoral is up to the individual. 
5. Moral standards are simply personal rules which indicate how a person should behave, and are not to be applied in making judgments of others.

6. Ethical considerations in interpersonal relations are so complex that individuals should be allowed to formulate their own individual codes.

7. Rigidly codifying an ethical position that prevents certain types of actions could stand in the way of better human relations and adjustment.

\section{Corporate ethical values (Hunt et al., 1989)}

1. Managers in my company often engage in behavior that I consider to be unethical.

2. In order to succeed in my company, it is often necessary to compromise one's ethics.

3. Top management in my company has let it be known in no uncertain terms that unethical behaviors will not be tolerated.

4. If a manager in my company is discovered to have engaged in unethical behavior that results in personal gain (rather than corporate gain), he or she will be promptly reprimanded.

5. If a manager in my company is discovered to have engaged in unethical behavior that results in corporate gain (rather than personal gain), he or she will be promptly reprimanded. 


\section{REFERENCES}

Abramson, M.: 1985, “The Autonomy-Paternalism Dilemma in Social Work Practice”, Social Casework, 66, 387-393.

Arslan, M.: 2001, "The work ethic values of Protestant British, Catholic Irish and Muslim Turkish managers", Journal of Business Ethics, 31, 321-340.

Australian Bureau of Statistics: 2007, Religious Affiliation by Age-Time Series Statistics (1996, 2001, 2006 Census Years), Available Online http://www.censusdata.abs.gov.au, Accessed on 31 July 2007.

Eagly, A. and W. Wood: 1991, "Explaining Sex Differences in Social Behavior: A MetaAnalytic Perspective", Personality and Social Psychology Bulletin, 17, 306-321.

Fernando, M.: 2007, "Corporate Social Responsibility in the Wake of the Asian Tsunami: A Comparative Case Study of Two Sri Lankan Companies", European Management Journal, 25(1), 1-10.

Ferrell, O.C., and L.G. Gresham: 1985, “A Contingency Framework for Understanding Ethical Decision Making in Marketing”, Journal of Marketing, 49, 87-96.

Forsyth, D.R.: 1992, "Judging the Morality of Business Practices: The Influence of Personal Moral Philosophies", Journal of Business Ethics, 11, 461-470.

Forsyth, D.R., J.L. Nye and K. Kelley: 1988. "Idealism, Relativism, and the Ethic of Caring", Journal of Psychology, 122, 243-248.

Forsyth, D.R.: 1980, “A Taxonomy of Ethical Ideologies", Journal of Personality and Social Psychology, 39 (1), 175-184.

Franke, G.R., D.F. Crown and D.F. Spake: 1997, “Gender Differences in Ethical Perceptions of Business Practices", Journal of Applied Psychology, 82, 920-934. 
Gilligan, C.: 1982, In a Different Voice: Psychological Theory and Women's Development (Harvard University Press, Cambridge, MA).

Hall, E.T.: 1976, Beyond Culture (Anchor Books, Doubleday, Garden City, NY).

Henle, C., R. Giacalone and C. Jurkiewicz: 2005, "The Role of Ethical Ideology in Workplace Deviance", Journal of Business Ethics, 56, 219-230.

Hunt, S.D., and S. Vitell: 1993, "The General Theory of Marketing Ethics: A Retrospective and Revision”, in N.C. Smith, J. A. Quelch (eds), Ethics in Marketing (Irwin, Homewood, IL.).

Hunt, S.D. and S. Vitell: 1986, “A General Theory of Marketing Ethics", Journal of Macromarketing, 8, 5-16.

Hunt, S.D., V.R. Wood and L.B. Chonko: 1989, "Corporate Ethical Values and Organizational Commitment in Marketing", Journal of Marketing, 53, 79-90.

Jansen, E., and M.A. Vin Glinow: 1985, "Ethical Ambience and Organizational Reward Systems", Academy of Management Review, 10 (4), 814-822.

Karande, K., C.P. Rao and A. Singhapakdi: 2002, "Moral Philosophies of Marketing Managers: A Comparison of American, Australian, and Malaysian Cultures", European Journal of Marketing, 36(7/8), 768-791.

Kohlberg, L.: 1976, "Moral Stages and Moralization", in T. Lickona (ed.), Moral Development and Behavior: Theory, Research, and Social Issues (Holt, Rinehart and Winston, New York).

Kohlberg, L.: 1981, The Meaning and Measurement of Moral Development (Clark University Press, Worcester, MA). 
Kohlberg, L.: 1983, Moral Stages: A Current Formulation and a Response to Critics (Karger, New York).

Laczniak, G.R., and E.J. Inderrieden: 1987, “The Influence of Stated Organizational Concern Upon Ethical Decision Making”, Journal of Business Ethics, 6(4), 297-307.

Ladd, J.: 1991, "The Quest for a Code of Professional Ethics: An Intellectual and Moral Confusion", in Deborah Johnson (ed.), Ethical Issues in Engineering (Prentice Hall, New Jersey).

Loewenberg, F., and R. Dolgoff: 1996, Ethical Decisions for Social Work Practice (F. E. Peacock, New York).

Longenecker, J.G., J.A. Mckinney and C.W. Moore: 2004, "Religious Intensity, Evangelical Christianity, and Business Ethics: An Empirical Study”, Journal of Business Ethics, 55, 373-386.

Reamer, F.: 1990, Ethical Dilemmas in Social Service (Columbia University Press, New York).

Singhapakdi, A., S. Salyachivin, B. Virakul, and V. Veerayangkur: 2000, "Some Important Factors Underlying Ethical Decision-Making of Managers in Thailand", Journal of Business Ethics, 27(3), 271-285.

Singhapakdi, A., K.L. Kraft, S.J. Vitell and K.C. Rallapalli: 1995, “The Perceived Importance of Ethics and Social Responsibility on Organizational Effectiveness: A Survey of Marketers", Journal of Academy of Marketing Science, 23 (1), 49-56.

Singhapakdi, A., S.J. Vitell and G.R. Franke: 1999, “Antecedents, Consequences, and Mediating Effects of Perceived Moral Intensity and Personal Moral Philosophies", Journal of The Academy of Marketing Science, 27(1), 19-35. 
Sparks, J.R., and S.D. Hunt: 1998, "Marketing Researcher Ethical Sensitivity: Conceptualization, Measurement, and Exploratory Investigation”, Journal of Marketing, 62(2), 92-109.

Taylor, S.J.: 2003. How Do Hofstede's Dimensions Correlate With The World's Religions?, The International Business Center Newsletter, April, Available Online, Http://www.Internationalbusinesscenter.Org/International_Newsletter/Volume2_Issue1. Htm , Accessed on January 8, 2006.

Terpstra, D.E., E.J. Rozell and R.K. Robinson: 1993, “The Influence of Personality and Demographic Variables on Ethical Decisions Related to Insider Trading”, The Journal of Psychology, 127(4), 375-389.

Trevino, L.K.: 1986, "Ethical Decision Making in Organizations: A Person-Situation Interactionist Model", Academy of Management Review, 11(3), 601-617.

Vitell, S.J., and A. Singhapakdi: 1993, "Ethical Ideology and its Influence on the Norms and Judgments of Marketing Practitioners", Journal of Marketing Management, 3, 1-11.

Weeks, W.A., and J. Nantell: 1992, "Corporate Codes of Ethics and Sales Force Behavior: A Case Study”, Journal of Business Ethics, 11(10), 753-60. 
TABLE 1

Profile of the Study Sample (N=80)

\begin{tabular}{|l|c|}
\hline & \% \\
\hline Age & 0.01 \\
\hline Under 30 & 11.2 \\
\hline $31-40$ & 47.5 \\
\hline $41-50$ & 32.5 \\
\hline $51-60$ & 0.07 \\
\hline $61-70$ & \\
\hline & \\
\hline Gender & 86.2 \\
\hline Male & 13.8 \\
\hline Female & \\
\hline & \\
\hline Years in business & 0.9 \\
\hline Under 5 & 0.9 \\
\hline $5-10$ & 0.1 \\
\hline $11-15$ & 0.2 \\
\hline $16-20$ & 41.3 \\
\hline $21-30$ & 18.7 \\
\hline Over 30 & \\
\hline & \\
\hline Current job title & 0.01 \\
\hline President & 21.2 \\
\hline CEO & 17.5 \\
\hline Director & 23.7 \\
\hline Group GM & 17.5 \\
\hline GM & 13.7 \\
\hline Senior Manager & 0.03 \\
\hline Manager & 0.03 \\
\hline Other & \\
\hline Religion & 73.8 \\
\hline Christian & 0.01 \\
\hline Buddhist & 25 \\
\hline Other & \\
\hline & \\
\hline
\end{tabular}


TABLE 2

Descriptive Statistics

\begin{tabular}{|l|c|c|c|}
\hline Variables & Geometric Mean & $\begin{array}{r}\text { Geometric Standard } \\
\text { deviation. }\end{array}$ & 95\% Confidence \\
& & & \\
\hline Idealism & 22.9 & 1.2 & $15.9-17.1$ \\
Relativism & 16.4 & 1.3 & $15.1-16.4$ \\
$\begin{array}{l}\text { Corporate } \\
\text { Ethical } \\
\text { Values }\end{array}$ & 15.8 & 1.2 & \\
\hline
\end{tabular}


TABLE 3

Geometric Means (Geometric Standard Deviations) of the Idealism, Relativism and Corporate Ethical Values Scores by Demographic Characteristics

\begin{tabular}{|l|c|c|c|}
\hline & Idealism & Relativism & $\begin{array}{c}\text { Corporate Ethical } \\
\text { Values }\end{array}$ \\
\hline $\begin{array}{l}\text { Religion } \\
\text { Christian }\end{array}$ & $23.6(1.2)$ & $15.9(1.1)$ & $15.9(1.2)$ \\
& $20.9(1.1)^{*}$ & $18.1(1.1)^{*}$ & $15.5(1.2)$ \\
\hline Age & $22.6(1.3)$ & $19.5(1.2)$ & $13.5(1.1)$ \\
Under 40 & $23.3(1.1)$ & $16.1(1.2)^{* *}$ & $16.1(1.2)^{*}$ \\
Above 50 & $22.4(1.3)$ & $16.4(1.3)^{* *}$ & $16.3(1.2)^{* *}$ \\
\hline Gender & $22.9(1.2)$ & $16.4(1.3)$ & $15.9(1.1)$ \\
Male & $22.4(1.2)$ & $18.1(1.2)$ & $14.9(1.2)$ \\
Female & & & $16.4(1.2)$ \\
& & & $15.6(1.2)$ \\
\hline Current job title & $22.9(1.2)$ & $15.9(1.2)$ & \\
Director and above & $22.4(1.2)$ & $16.8(1.3)$ & \\
Others & & & \\
& & & \\
\end{tabular}

${ }^{*} \mathrm{p}<0.1$.

$* * \mathrm{p}<0.05$. 
FIGURE 1

Theoretical Frameworks for Idealism and Relativism
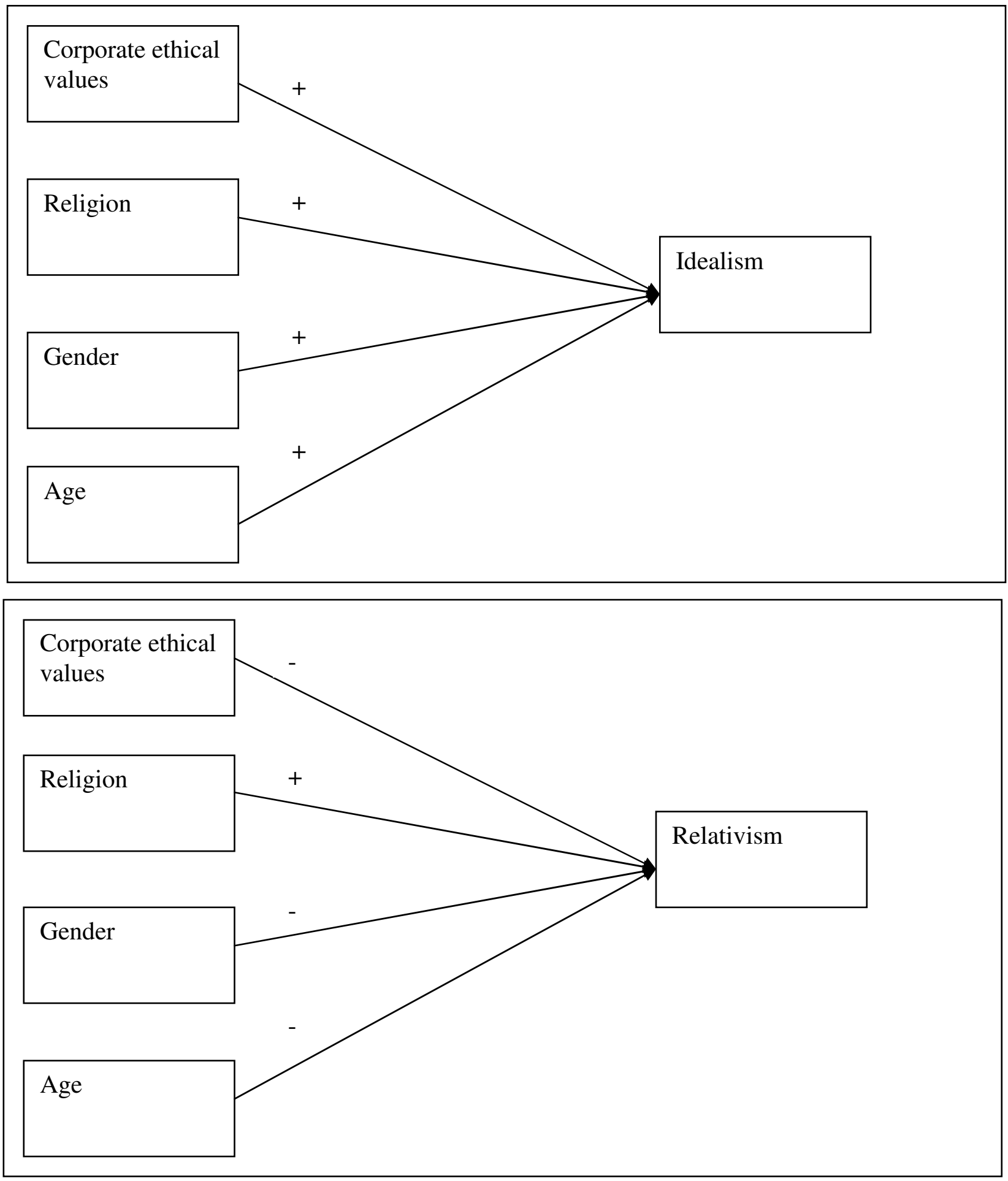